\title{
From global complexity to local reality Aligning implementation pathways for the Sustainable Development Goals and landscape approaches
}

\author{
James Reed, Josh van Vianen and Terry Sunderland
}

\begin{abstract}
Introduction
The Global Landscapes Forums held in Warsaw (November 2013) and Lima (December 2014), coupled with the CGIAR Development Dialogues (New York, September 2014), have helped position 'landscape approaches' at the center of sustainable development initiatives and global discourse. The Center for International Forestry Research (CIFOR) and its many partners continue to devise ways to best introduce a holistic and integrated 'landscapes' approach to balance trade-offs between conservation and development, including agriculture, with the aim of influencing both policy and practice.
\end{abstract}

The adoption of the United Nations Sustainable Development Goals (SDGs) in September this year, following a more than two-year process of open negotiation, is very timely. The 17 goals, with their 169 targets, provide an ambitious set of objectives for the 200+ nations that have committed to "end poverty" (Goal 1), "end hunger" (Goal 2), and "protect, restore and promote sustainable use of terrestrial ecosystems" (Goal 15), among others. These goals represent a departure from the Millennium Development Goals (MDGs) that have guided the global development agenda during 2000-2015. The UN SDG report now applies to all countries and nation states irrespective of development status, making commitment to the SDGs a truly global endeavor (UNGA 2015).

\section{From MDGs to SDGs}

The MDGs contributed to fostering better collaboration between nation states, donors and disciplines, and have helped deliver many significant and tangible achievements. Some positive outcomes that have been achieved during the tenure of the MDGs - though not necessarily as a direct result - include: halving global poverty (five years prior to the target deadline) and child mortality, and almost halving undernourishment and maternal mortality. However, the MDGs were not without criticism - the process of negotiating the goals was criticized for its lack of inclusiveness. Similarly there was the suggestion that the goals did not sufficiently address pressing environmental concerns, being largely aimed at developing countries. As a whole, there was some criticism that the use of diffuse, nonspecific targets could see goals accomplished without sufficiently addressing the needs of those most vulnerable. For example, it has been suggested that the goal of halving global poverty (MDG Target $1 \mathrm{~A})$ was facilitated by strong economic growth in specific countries (particularly China) and also lifting up those closest to the USD 1.25 (revised to USD 1.90) poverty line. Thus failing to account for those at the most extreme end of the poverty spectrum.
The SDGs are an attempt to advance the development agenda by reconciling and building upon both the successes and some of the shortcomings of the MDGs. The lengthy consultative global process of negotiation to formulate the goals following the Rio+20 conference has been commendable. Biodiversity conservation and global climate change are more central and the goals are more inclusive of developed countries. The current goals are ambitious and will require a high degree of enthusiasm and resourcefulness for members to meet their commitments; if anything there is concern that the goals are somewhat overambitious, which could result in a lack of focus and potentially become a limiting factor to achieving overall targets.

In the transition period from the MDGs to SDGs, it is important to reflect on both the successes and shortcomings of the last 15 years and look forward to the challenges and opportunities presented by the SDGs. Key factors that contributed to the successes of the MDGs were the collaborative efforts within and between countries and the ability to track progress against robust indicators. It is widely acknowledged that the success of the SDGs depends on our ability to integrate efforts across all the stated goals and commit both technical and financial support accordingly (Mbow et al. 2015). Consensus is also required on which implementation strategies are most appropriate and in what context. Agreement is also needed on how progress should be measured and monitored and the resultant information disseminated in a tangible, transparent and comprehensible manner Griggs et al. 2013). We urgently need to learn lessons from both successes and what might be regarded as failures in approach. Here, we present some initial suggestions for how an integrated landscape approach to reconciling competing land uses can - under the right circumstances - be an appropriate implementing mechanism for achieving the SDG targets.

\section{The landscape approach}

A landscape approach can be defined as a framework to integrate policy and practice for multiple competing land uses through the implementation of adaptive and integrated management systems (Reed et al. 2015). It is a multi-faceted, long-term and collaborative process that aims to bring together multiple stakeholders from multiple sectors to provide solutions at multiple scales. In doing so, the process is designed to facilitate negotiation between stakeholders in order to reconcile and negotiate for trade-offs and maximizing synergies with the overall objective of 'winning more' and 'losing less' (Sayer et al. 2013). 


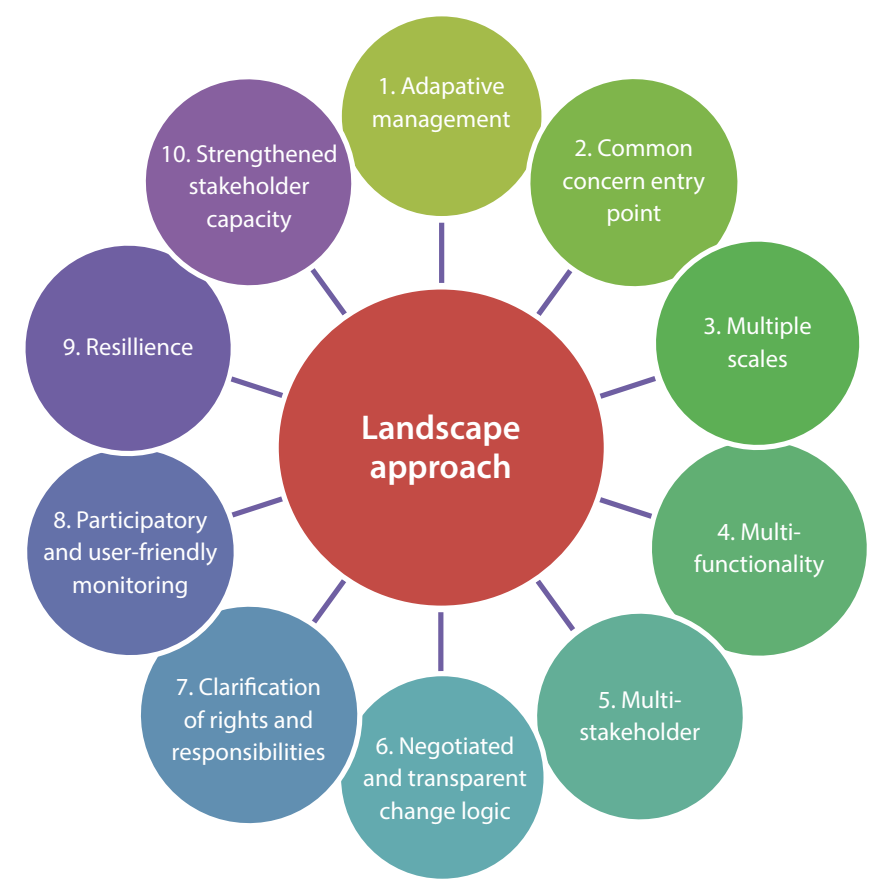

Figure 1. Ten principles for a landscape approach

Source: Sayer et al. 2013

When attempting to institute a landscape approach, the emphasis needs to be on the engagement of all stakeholders from the outset. This is in order to identify the individual and collective requirements and expectations from implementing the landscape approach. There needs to be continued dialogue and emphasis on good governance and compromise, but also effective facilitation and leadership, identifying the optimal methods for overcoming power asymmetries and building the capacity of local, and particularly marginalized stakeholders. Evaluation of progress that can feed into adaptive management mechanisms to identify and adjust for potentially negative outcomes is a key tenet of integrated landscape management, which is designed to account for trade-offs by acting upon synergies and opportunities to enhance positive, and mutually beneficial, outcomes. It is also crucial to acknowledge that the objectives sought are not likely to be accomplished within the typical project time frame - a landscape approach must be recognized as a long-term endeavor, a 'process' rather than a 'project' (Figure 1).

Achieving the targets of the SDGs will be dependent on aligning global objectives with local realities. Inherent in any landscape approach is the need to work across multiple scales and contexts, and selecting appropriate biophysical, political and geographical boundaries is crucial. All landscapes vary in size, shape and land use configuration, and selecting boundaries should be dependent on the needs and objectives of stakeholders across all levels. Ideally, the spatial dimensions need to be large enough to capture the full suite of interacting stakeholders, and meaningful amounts of biodiversity and ecosystem services. At a recent workshop for landscape researchers and practitioners (James Cook University, June 2015) it was unanimously agreed that for a landscape approach to be effective, contextualization will be an important factor in decision making. For example, catchments make sense as boundary points for integrating water and land management. Meanwhile, political boundaries such as municipalities, states and countries makes sense for interacting with processes of change in relation to governance and policy (personal comm. J Barlow, 2015).

All landscapes are dynamic and evolving, and are subject to variable and unequal biophysical, climatic and anthropogenic pressures. As such, the optimal landscape approach strategy in a given landscape may not be as effective in another landscape and may require considerable adjustments in order to build landscape-specific resilience and resistance to shocks and changes. It is important to recognize that under some circumstances, a landscape approach may be maladapted to the system of interest, and in such cases a more sectorial approach may be more appropriate.

\section{Landscape approach and SDGs: Overlaps and interlinkages}

At first glance, the SDG targets appear to have maintained a sectorial focus despite the UN SDG report expressing the need for "holistic and integrated approaches" to achieve the goals. However, the multiple interlinkages within and between goals and targets are clear. These linkages present opportunities and challenges for implementing partners. In some scenarios, addressing one target will naturally complement efforts toward another target, while conversely it may be that efforts toward a particular target may conflict with the aims of another. As such, it would be remiss not to think holistically about how these targets can be achieved.

At the global scale, sustainable development is necessarily the overarching framework (Hanspach et al. 2013). At the national level - the scale at which implementation efforts are likely to be formulated - integrated landscape approaches provide considerable potential (Milder et al. 2014). Effective implementation could achieve many of the targets concurrently, while addressing the interlinked challenges in a clear and transparent manner (e.g. targets 16.6 and 16.7). As part of a recently conducted review, we identified where overlaps between landscape approach frameworks and the objectives of the SDGs exist and which goals would most benefit from adopting a landscape approach framework. For this process, we assessed the extent to which each of the 169 targets would benefit from the philosophies of the landscape approach (scoring 1-4 for each, where 1 = vital, 4 = not applicable), and then took the average of these to identify how appropriate a landscape approach framework is to each of the 17 SDGs.

By addressing each of the specific targets, we have provided a more nuanced assessment of the applicability of the landscape approach. For example, at the broader 'goal' scale, it could be argued that the landscape approach, by attempting to reconcile conflicting objectives within landscapes, is useful to all 17 goals in some way. However, if we take the example of Goal 16 (Promote peaceful and inclusive societies for sustainable development, provide access to justice for all and build effective, accountable and inclusive institutions at all levels) our classification shows that while appearing to display a good fit, the detail provided by the individual targets led us to conclude that the landscape 
approach may not be suitable. For example, we did not consider the landscape approach to be particularly relevant to targets such as 16.3 (promote the rule of law at the national and international levels and ensure equal access to justice to all), 16.4 (by 2030, significantly reduce illicit financial and arms flows...combat all forms of organized crime), 16.5 (substantially reduce corruption and bribery in all their forms), or 16.9 (by 2030, provide legal identity for all, including birth registration). Despite clear overlap with targets 16.6 (develop effective, accountable and transparent institutions at all levels) and 16.7 (ensure responsive, inclusive,

participatory and representative decision-making at all levels), the average applicability of the landscape approach to the 10 targets within Goal 16 made it inapplicable at the goal level.

We acknowledge this was a necessarily subjective process but feel the output adds value to the current discourse and can encourage further discussion (Table 1).

We acknowledge the need not to overprescribe any given pathway for implementation (Ostrom et al. 2007) and accept that landscape approaches are not a panacea to achieving all of the diverse and ambitious goals and targets. However, landscape

\section{Table 1. The applicability of the landscape approach as an implementing framework to address the Sustainable Development Goals.}

\begin{tabular}{|c|c|c|}
\hline $\begin{array}{c}\text { Goal } \\
\text { number }\end{array}$ & Sustainable Development Goal description & $\begin{array}{l}\text { Landscape approach } \\
\text { applicability }\end{array}$ \\
\hline 1 & End poverty in all its forms everywhere & Important \\
\hline 2 & $\begin{array}{l}\text { End hunger, achieve food security and improved nutrition and promote } \\
\text { sustainable agriculture }\end{array}$ & Important \\
\hline 3 & Ensure healthy lives and promote well-being for all at all ages & Relevant \\
\hline 4 & $\begin{array}{l}\text { Ensure inclusive and equitable quality education and promote lifelong learning } \\
\text { opportunities for all }\end{array}$ & Relevant \\
\hline 5 & Achieve gender equality and empower all women and girls & Relevant/Not applicable \\
\hline 6 & Ensure availability and sustainable management of water and sanitation for all & Vital \\
\hline 7 & Ensure access to affordable, reliable, sustainable and modern energy for all & Relevant \\
\hline 8 & $\begin{array}{l}\text { Promote sustained, inclusive and sustainable economic growth, full and } \\
\text { productive employment and decent work for all }\end{array}$ & Relevant \\
\hline 9 & $\begin{array}{l}\text { Build resilient infrastructure, promote inclusive and sustainable } \\
\text { industrialization and foster innovation }\end{array}$ & Relevant \\
\hline 10 & Reduce inequality within and among countries & Relevant \\
\hline 11 & Make cities and human settlements inclusive, safe, resilient and sustainable & Relevant \\
\hline 12 & Ensure sustainable consumption and production patterns & Relevant \\
\hline 13 & Take urgent action to combat climate change and its impacts & Important \\
\hline 14 & $\begin{array}{l}\text { Conserve and sustainably use the oceans, seas and marine resources for } \\
\text { sustainable development }\end{array}$ & Important \\
\hline 15 & $\begin{array}{l}\text { Protect, restore and promote sustainable use of terrestrial ecosystems, } \\
\text { sustainably manage forests, combat desertification, and halt and reverse land } \\
\text { degradation and halt biodiversity loss }\end{array}$ & Vital \\
\hline 16 & $\begin{array}{l}\text { Promote peaceful and inclusive societies for sustainable development, } \\
\text { provide access to justice for all and build effective, accountable and inclusive } \\
\text { institutions at all levels }\end{array}$ & Not applicable \\
\hline 17 & $\begin{array}{l}\text { Strengthen the means of implementation and revitalize the global partnership } \\
\text { for sustainable development }\end{array}$ & Relevant \\
\hline
\end{tabular}

Vital = Goal unlikely to be achieved without a landscape approach

Important = Landscape approach would be a suitable framework for achieving these goals

Relevant $=$ Goals could benefit from adopting the philosophies of the landscape approach

Not applicable $=$ Landscape approach unlikely to be applicable.

Note: Classification was achieved by assessing the applicability of the landscape approach to each of the 169 targets and then taking the average'score'for each goal. 
approach frameworks provide an effective pathway to achieving many specific targets, and the philosophies and tools derived from such approaches show promise in being useful across the broad spectrum of goals and indicators.

Our assessment of how landscape approach frameworks could be applied to each of the individual targets (Table 1) has enabled us to hypothesize the ways in which these ideas might be applied on the ground.

Many sectors and land uses are dependent on the effective management of the same natural resource base. Lack of coordination among sectors will likely have negative outcomes for the management of shared natural resources and thus the achievement of SDG targets. Despite the fact that many goals are interlinked, the current individual targets are highly sectorial in nature. However, sectorial efforts to achieve individual targets in isolation are only likely to succeed at the expense of others (Gaffney 2014).

For example, Goal 6 and the associated targets 6.2 (access to sanitation and hygiene), 6.5 (adoption of integrated water resources management) and 6.6 (protection and restoration of aquatic ecosystems) are clearly linked, not only because it is explicitly stated in Target 6.5 but also because it is inherent that failing to protect aquatic ecosystems will result - in most parts of the developing world - in reduced access to clean water and sanitation.

A landscape approach is not only an appropriate framework for integrating targets within goals, but due to its potential to reconcile multiple objectives can be applied across goals. A landscape approach could link the above example with targets from other goals. For instance, ensuring sustainable food production systems (Target 2.4) and sustainable management of all forests (Target 15.2), and integrating climate change measures into national polices, strategies and planning (Target 13.2), all offer the potential for synergies with the targets of Goal 6. Likewise, the appropriate management systems of upstream water and forest resources will have downstream effects, in terms of run off and pollution, that will ultimately affect the ability to sustainably manage and conserve coastal marine ecosystems (targets 14.2 and 14.5). All of these interlinked examples could influence the ability to achieve some of the broader and less well-bounded targets, such as 1.5 (build the resilience of the poor to climate, economic, social and environmental shocks).

Theoretically, the appropriate application of a landscape approach will ensure the development of long-term selfregulating transparent institutions for ensuring not only the achievement of SDG targets - which is in itself covered in targets 16.6 and 16.7 - but achieving ongoing, long-term sustainability beyond the time frames within the SDGs.

In some landscapes, not all of these interlinkages will have the same degree of connectedness or interdependence, meaning one size will not fit all. As such, it is imperative to develop implementation pathways that contribute to national commitments to global policy and are cognizant of local realities (see below).

\section{Challenges and recommendations}

As we have illustrated above, a landscape approach shows considerable potential as an implementing framework for addressing many of the SDGs and their targets. When applied effectively, it can aid efforts to alleviate poverty in an equitable manner, conserve biodiversity, safeguard forests and facilitate the sustainable management of natural resources, whilst maintaining sustainable food production and providing resilience to the environmental and economic impacts of climate change. However, while there is cause for cautious optimism, significant challenges remain. We present three key challenges that landscape researchers, practitioners and policy makers need to consider when applying landscape approaches to meet the SDG targets.

\section{Embracing integration}

The UN SDG report emphasizes that the fulfillment of the goals will require holistic and integrated approaches. Landscapes are inherently challenging and provide a classic 'wicked problem' - engaging multiple actors, operating at multiple levels and across multiple scales. We consider that overcoming traditional sectorial barriers at research, practice and policy levels is fundamental to accomplishing targets across multiple goals. Inter- and trans-disciplinary research and practice is the optimal method for arriving at solutions to complex challenges. Landscape researchers need to develop interdisciplinary skill sets but also be able to recognize when engaging researchers from diverse backgrounds will be most appropriate to deliver optimal outcomes, whilst having the necessary soft skills required to facilitate such multi-level engagement. At the practitioner level, when a landscape approach is adopted, there must be a transformational change in attitudes away from the sectorial approach of focusing on enhancing production, improving water quality or conserving forests etc. Practitioners need to be prepared to negotiate, compromise and accept that the greater good may impact their own objectives in the short term, but should result in more sustainable and productive landscapes for more people in the longer term.

Finally, it is no longer acceptable for decision makers to implement policy change without being fully cognizant of the impacts of their decisions on other sectors operating within the landscape, including the needs and requirements of local stakeholders. This will require more engagement at the ministerial level, something we are not used to, but an area in which there have been positive recent developments with the merging of ministries in Turkey (Forest and Environment with Public Works and Housing) and Indonesia (Forest with Environment) for example.

\section{Optimal implementation}

Providing solutions to complex challenges may require working across disciplines and scales and producing complex solutions. However, interventions within a landscape need to be scalable, and if we cannot provide recommendations for actions at the local level that stakeholders can identify with, there is the risk of further marginalizing vulnerable groups. The ability to disaggregate complex integrated solutions at the landscape level and downscale to more comprehensible recommendations at the local practitioner level will be 
necessary to generate support toward more effective implementation. Conversely, the ability to upscale and outscale landscape approaches can be equally valuable. A key principle of landscape approaches is identifying a common concern entry point (i.e. a shared resource limitation or a particular conflict over land use - that could also be a locally relevant SDG target). The literature shows numerous examples where a common focus and the capacity to then upscale has enabled the attainment of conflicting goals, such as improving livelihoods and sustainably managing natural resource use.

Processes for implementation should be framed around a negotiated and transparent theory of change (Sayer et al. 2013). The development of the theory of change needs to be inclusive and open to all stakeholders, both internal and external to the landscape. As alluded to above, there should be a shared understanding of the long-term nature of landscape approaches. Defining ultimate end points may be less valuable than identifying how progress is going to be maintained toward objectives. As such, stakeholders need to identify both the financial mechanisms and technical capacities to support landscape approach implementation and ongoing evaluation, particularly after project funding has expired. Recommendations include developing networks and building capacity through institutional support, and engaging fully with public-private platforms and donor agencies. Despite the considerable rhetoric, current donor models for conservation and development are inherently maladapted to the philosophies of the landscape approach - and therefore largely the SDGs - and policy makers, researchers and practitioners need to provide good justifications to stimulate change in how donor funding is distributed and allocated.

\section{Developing appropriate metrics}

This is perhaps the missing part of the puzzle in the UN SDG report. Currently, the methods for selecting indicators and measuring progress toward the goals are still in development. As the report attests "such data is key to decision-making" and it could be argued that the availability of such data and the accountability this instills was a large contributing factor in the success of the MDGs. There is little doubt that the development of indicators and methods for monitoring are fundamental to achieving the SDG's, and yet this process remains a significant challenge. Similarly, there has been considerable debate over the most suitable methods for evaluating the effectiveness of landscape approaches. While this is indeed a challenge, there is a body of established and contemporary evidence developed with recommendations on what types of indicators to apply and how to measure progress (Bebbington and Perreault 1999; Bond and Mukherjee 2002; Aldrich and Sayer 2007; Sayer et al. 2007; Belcher et al. 2012). Governments that are pursuing integrated approaches to address the SDGs would be well advised to take heed of the available evidence-based research on landscape monitoring and assessment. Likewise, policy makers should be encouraged to work with landscape researchers and stakeholders in efforts to concurrently develop complementary sets of indicators that can be utilized for both landscape approaches and monitoring toward progress on national commitments.

\section{Conclusions}

The SDGs represent a significant challenge and opportunity for the global community. The MDGs have taught us that progress toward overcoming persistent global challenges - such as poverty, hunger and environmental sustainability - is achievable through targeted and well-monitored collaborative efforts. We now have the opportunity to develop innovative and integrated approaches to help meet the challenge presented by the even more ambitious SDGs. The landscape approach is one strategy that - when applied effectively - has the potential to address multiple targets both within and between the goals agreed in the new UN development agenda. This infobrief clearly illustrates the overlaps between the philosophies of the landscape approach and the objectives of the SDGs. In doing so, we hope to add value to the current landscape and sustainability science discourse by generating further discussion among landscape researchers and practitioners on best practices for implementation and monitoring progress, and issue a challenge to policy makers to recognize the landscape approach as a viable implementing framework to achieve multiple goals.

\section{References}

Aldrich M and Sayer J. 2007. In Practice: Landscape Outcomes Assessment Methodology "LOAM". WWF Forests for Life Programme.

Bebbington A and Perreault T. 1999. Social capital, development, and access to resources in highland Ecuador. Economic Geography 75:395-418.

Belcher B, Bastide F, Castella JC and Boissiere M. 2012 Development of a village-level livelihood monitoring tool: A case-study in Viengkham District, Lao PDR: Desarrollo de una herramienta de monitoreo de medios de subsistencia a escala de comunidad: Un estudio de caso del distrito de Viengkham, RDP Lao. International Forestry Review 15:48-59.

Bond R and Mukherjee N. 2002. Livelihood asset status tracking: An impact monitoring tool? Journal of International Development 14:805-15.

Gaffney O. 2014. Sustainable Development Goals: Improving human and planetary wellbeing. Global Change magazine. 20-23.

Griggs D et al. 2013. Policy: Sustainable development goals for people and planet. Nature 495:305-7.

Hanspach J et al. 2013. Develop, then intensify. Science 341(6147):713.

Mbow C, Neely C and Dobie P. 2015. How can an integrated landscape approach contribute to the implementation of the Sustainable Development Goals (SDGs) and advance climate-smart objectives? In Minang PA, van Noordwijk M, Freeman OE, Mbow C, de Leeuw J and Catacutan D, eds. Climate-smart landscapes: Multifunctionality in practice. Nairobi, Kenya: World Agroforestry Center (ICRAF).103-116. http://www.asb.cgiar.org/book/climate-smart-landscapesmultifunctionality-practice\#sthash.5ecKc5eC.dpuf

Milder JC, Hart AK, Dobie P, Minai J and Zaleski C. 2014. Integrated landscape initiatives for African agriculture, development, and conservation: A region-wide assessment. World Development 54:68-80. 
Ostrom E, Janssen MA and Anderies JM. 2007. Going beyond panaceas. Proceedings of the National Academy of Sciences of the United States of America 104:15176-8.

Reed J, Deakin L and Sunderland T. 2015. What are 'Integrated Landscape Approaches' and how effectively have they been implemented in the tropics: A systematic map protocol. Environmental Evidence 4:1-7.

Sayer J et al. 2007. Assessing environment and development outcomes in conservation landscapes. Biodiversity and Conservation 16:2677-94.
Sayer J et al. 2013. Ten principles for a landscape approach to reconciling agriculture, conservation, and other competing land uses. Proceedings of the National Academy of Sciences of the United States of America 110:8349-56.

[UNGA] United Nations General Assembly. 2015. Transforming our world: The 2030 Agenda for Sustainable Development (A) RES/70/1). New York: United Nations.

\begin{tabular}{|c|c|c|}
\hline CGIAR & $\begin{array}{l}\text { RESEARCH } \\
\text { PROGRAM ON } \\
\text { Forests, Trees and } \\
\text { Agroforestry }\end{array}$ & $\begin{array}{l}\text { Produced by CIFOR as part of the CGIAR Research Program on Forests, Trees and Agroforestry } \\
\text { (CRP-FTA). This collaborative program aims to enhance the management and use of forests, } \\
\text { agroforestry and tree genetic resources across the landscape from forests to farms. CIFOR leads } \\
\text { CRP-FTA in partnership with Bioversity International, CATIE, CIRAD, the International Center for } \\
\text { Tropical Agriculture and the World Agroforestry Centre. }\end{array}$ \\
\hline
\end{tabular}

CGIAR | Fund

